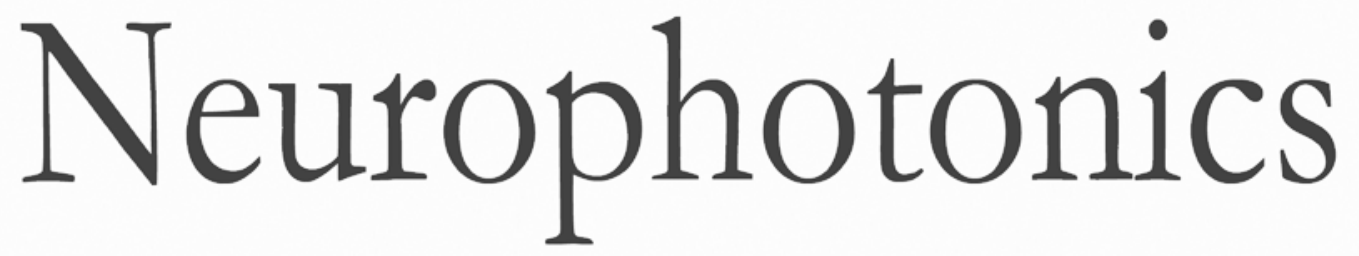

Neurophotonics.SPIEDigitalLibrary.org

\title{
Neurophotonics Pioneers and News
}

\author{
David Boas
}

\section{SPIE.}




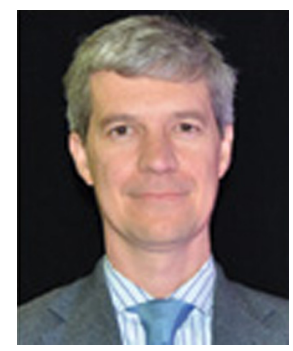

\section{Neurophotonics Pioneers and News}

In the early stages of launching Neurophotonics, the former Editor-in-Chief of the Journal of Biomedical Optics, Bruce Tromberg, suggested to me that we should initiate a series honoring Pioneers in Neurophotonics. Indeed, this not only provides a special and unique opportunity to recognize a true pioneer in the field, but also provides those whose careers have benefited from learning from and working with the Pioneer an opportunity to make a contribution in that person's honor. Over the coming years, we will launch calls to honor other pioneers, and we welcome suggestions. For the first Pioneer tribute, though, the choice was easy. It is with great pleasure that we launch our series on Pioneers in Neurophotonics by honoring Lawrence B. Cohen. He is truly the father of neurophotonics. I am very grateful to Brian Salzberg and Dejan Zecevic for their hard work in preparing this special section. I encourage you to read their introduction covering Professor Cohen's seminal contributions to neurophotonics.

In this issue we also introduce our "News and Comment" section with a news item summarizing a recent conference organized by the Society of Functional Near Infrared Spectroscopy. The publication of news items will serve our broader community by helping to highlight emerging hot topics and challenges in need of solutions. Neurophotonics spans many subdisciplines and numerous conferences. This breadth presents a barrier to raising awareness of emerging hot areas of research across the community. It is hoped that these news articles can help to reduce this barrier and increase awareness so that those outside of any given subdiscipline might learn about novel approaches and solutions that can be applied to accelerate scientific advancement. I encourage others to contact me regarding the submission of "News and Comment" items.

I am also pleased to announce that the Society for Functional Near Infrared Spectroscopy (SfNIRS) has adopted Neurophotonics as its official journal. As described in the news article, functional near infrared spectroscopy is rapidly growing with expanding applications ranging from advancing our understanding of the developing human brain, to its degeneration with aging and disease, and regeneration following injury. This is a mutually beneficial relationship between Neurophotonics and SfNIRS that we hope to repeat with other subdisciplines of neurophotonics.

\section{David Boas} Editor-in-Chief 